\title{
$\begin{array}{llll}N & O & T & E\end{array}$
}

\section{Bean Leaf Beetle (Coleoptera: Chrysomelidae) Preference for Two Phaseolus Beans Over Soybean ${ }^{1}$}

\author{
Meredith Shrader, Thomas Kuhar², Peter Schultz ${ }^{3}$, Douglas Pfeiffer, \\ and Katherine Kamminga
}

Department of Entomology, Virginia Tech, Blacksburg, Virginia 24061, USA

\author{
J. Entomol. Sci. 49(1): 87-90 (January 2014)
}

Key Words Cerotoma trifurcata (Förster); Snap bean; Lima bean; Feeding preference; host plant

In the eastern and central U.S., bean leaf beetle, Cerotoma trifurcata (Förster) (Coleoptera: Chrysomelidae), is a pest of legume crops, on which adults chew holes in leaves, can destroy seedlings, and can injure pods (Smelser and Pedigo 1992a, J. Econ. Entomol. 85: 2408 - 2412; Smelser and Pedigo 1992b, J. Econ. Entomol. 85: 2399 2403; Koch et al. 2005, Crop Prot. 24: 734 - 742). The beetle is also a primary vector of bean pod mottle virus, which can further reduce yield and seed quality in soybeans (Giesler et al. 2002, Plant Dis. 86: 1280 - 1289). On the Delmarva Peninsula, snap beans (Phaseolus vulgaris L.), lima beans (Phaseolus lunatus L.), and soybeans (Glycine max (L.) Merr.), are each important crops, and relatively high populations of $C$. trifurcata occur. To better understand the potential intercrop movement of the beetle and its implications for pest management, we conducted beetle host plant preference experiments.

In 2007, a small-plot field experiment was conducted in spring at the Virginia Tech Eastern Shore Agricultural Research and Extension Center (ESAREC) in Painter, VA, to determine if there was a beetle preference among 'Fordhook' bush lima beans, 'Bronco' snap beans, and 'Vigero V39N4RR' soybeans in the field. We compared both cotyledons (V1) and 4- leaf stage plants (V4). All beans were seeded in the greenhouse in 10-cm pots with Promix (Premier Horticulture, Quakertown, PA). The V4 plants were seeded in the greenhouse on 16 May, and the V1 beans were seeded on 30 May. All beans were transplanted in the field on 6 June. Prior to transplanting, the field was treated with $56 \mathrm{~kg} / \mathrm{ha}$ of nitrogen fertilizer and $0.37 \mathrm{~kg}[\mathrm{Al}] / \mathrm{ha}$ S-metolachlor preemergent herbicide (Dual Magnum, Syngenta Crop Protection, Inc., Greensboro, NC).

The experiment was arranged in a randomized complete block design with 4 replications. Within each replication, 5 sets of 5 plants of each of the 3 variety $\times 2$ growth stage combinations were arranged uniformly such that each treatment bordered all

\footnotetext{
${ }^{1}$ Received 5 May 2013; Accepted for publication 4 July 2013.

${ }^{2}$ Address correspondence (e-mail: tkuhar@vt.edu).

${ }^{3}$ Virginia Tech, Hampton Roads Agricultural Research and Extension Center, 1444 Diamond Springs Road, Virginia Beach, VA 23455, USA.
} 
other treatments. The row spacing was $36 \mathrm{~cm}$, with each row measuring $2 \mathrm{~m}$ in length. Twice weekly from 7 - 24 June (during the peak adult activity period of $C$. trifurcata in Virginia), we recorded the number of adults observed on all 25 plants for each of the 3 plant species $\times 2$ growth stage treatments per block. The first beetle count was made $1 \mathrm{~d}$ after transplanting beans in the field, and approximately twice weekly thereafter. Beetle count data were analyzed using an ANOVA and Tukey-Kramer HSD at $\alpha=0.05$ to separate means. Significantly more beetles were observed on 4-leaf stage snap beans and lima beans than any other plant species/growth stage combination $(F=19.4$; df $=5,23 ; P<0.0001$; Fig. 1$)$. The higher numbers of beetles on 4-leaf stage plants compared with cotyledons within plant species was probably the result of a larger $(\sim 3 x)$ plant area on which to encounter beetles. When comparing plants of equal growth stages, approximately twice as many beetles were found on snap bean and lima bean than soybean (Fig. 1).

A dual-choice test was performed in the laboratory at the ESAREC in Painter, VA in 2008 and 2009, to analyze the feeding preference of adult $C$. trifurcata for either 'Fordhook' bush lima bean, 'Bronco' snap bean, or 'Vigero V39N4RR' soybean foliage. Petri dishes (Fisher Brand $100 \times 15$ mm, Fisher Scientific, Pittsburgh, PA) were partially filled with $2 \%$ water agar to keep foliage moist. Fully-expanded leaves were collected from the field the morning of the experiment, and a large $5 \mathrm{~cm}^{2}$ hole-punch was used to cut leaf disks, which did not include the major leaf vein to allow for moreconsumable leaf area. Disks were paired by plant species and placed onto the water agar.

Adult $C$. trifurcata were collected by hand from wild legumes and beans in the field and starved for $24 \mathrm{~h}$ prior to testing. In the early afternoon, a single beetle (male or female) was placed in each Petri dish and allowed to feed on the leaf disks for $24 \mathrm{~h}$,

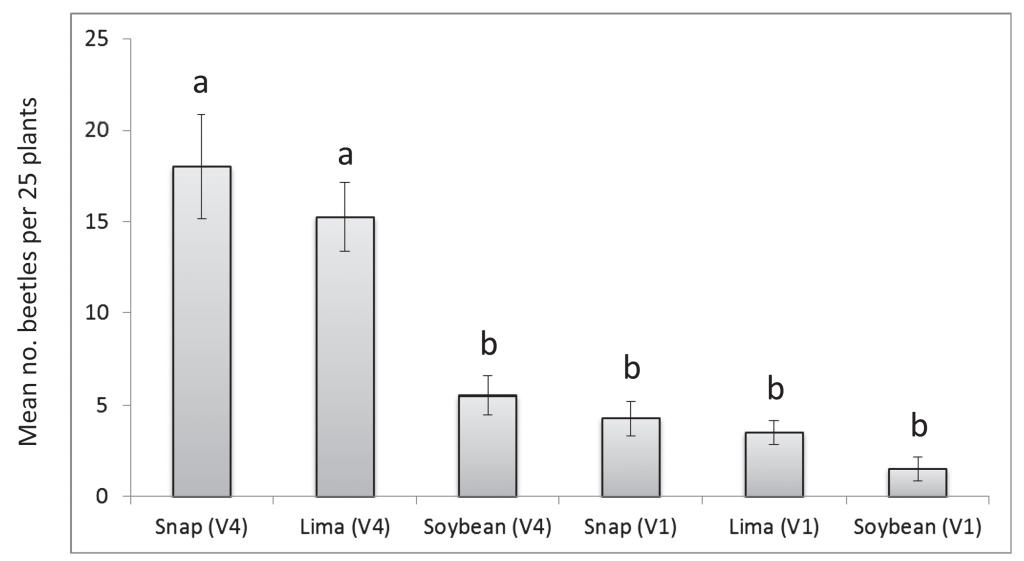

Fig. 1. Mean SE cumulative numbers of bean leaf beetles observed on 25 plants on six sample dates from 7 - 24 June within interplantings of 3 bean crops (snap bean, lima bean, and soybean) $\times 2$ growth stages (cotyledon [V1] and 4-leaf stage [V4]) in Painter, VA, 2007. Columns sharing the same letter are not significantly different according to ANOVA and TukeyKramer HSD at $\alpha=0.05$. 


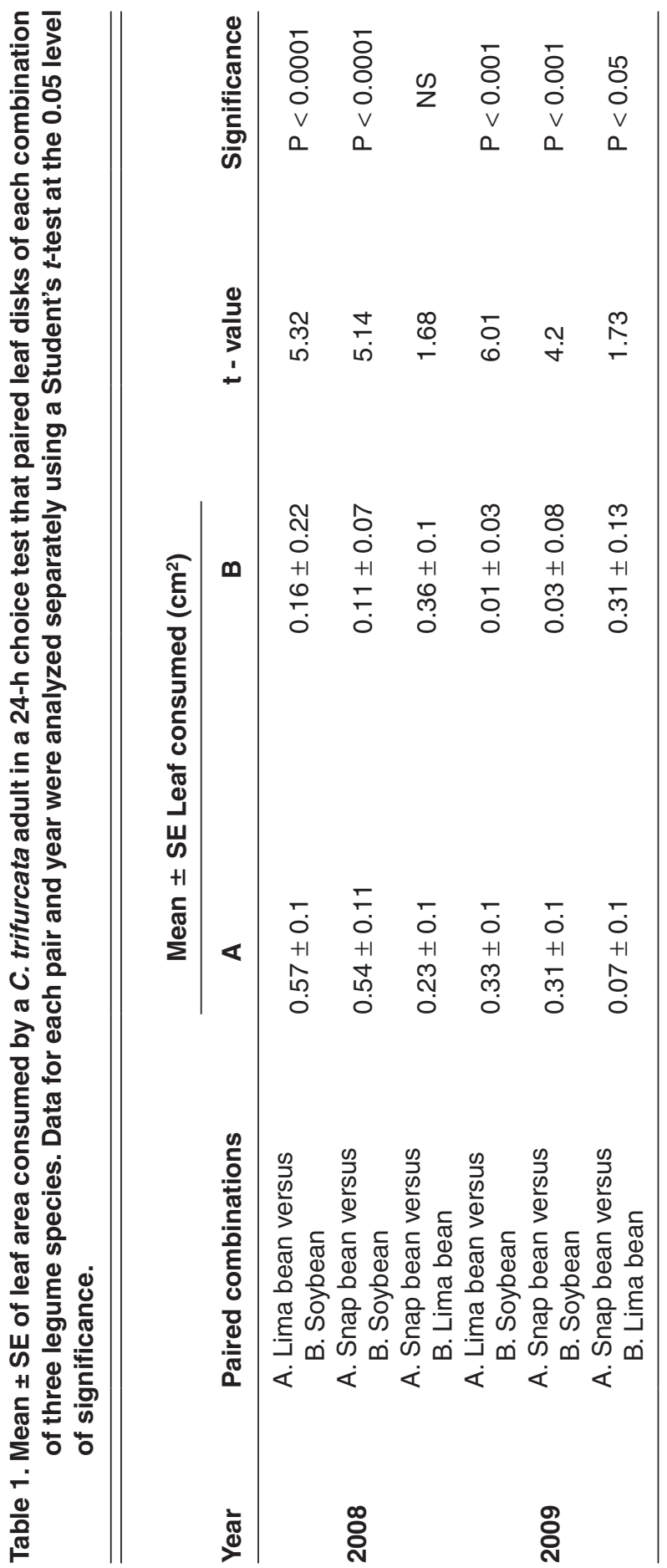


after which the leaf disks were removed and analyzed using a LI-COR model no. LI3100 leaf area meter (LI-COR Inc., Lincoln, NE) to obtain an accurate measurement of area consumed by each beetle. Each beetle in a Petri dish with paired leaf disks was considered a replication. Three paired-choice tests were performed: (1) lima bean versus soybean; (2) snap bean versus soybean; and (3) lima bean versus snap bean. In 2008, 40 replications of each paired test were performed, and in 2009, 20 replications were performed. Potential differences in leaf consumption between each of the paired combinations were analyzed using a paired Student's $t$-test with an $\alpha=0.05$.

In 2008, C. trifurcata consumed more snap beans $(P<0.0001)$ and lima beans $(P<0.001)$ than soybean and no differences were seen between snap bean and lima bean $(P=0.14)$ (Table 1). In 2009, snap beans $(P<0.001)$ and lima beans $(P<0.001)$ were chosen over soybeans; and, lima beans $(P<0.05)$ were preferred over snap beans.

Our experiments showed that, when given a choice, $C$. trifurcata adults preferred to feed upon leaf disks of snap bean or lima bean over soybean. Henn (1989, M.S. Thesis, Univ. Illinois, Urbana) also found that $C$. trifurcata preferred to feed on Phaseolus spp., over soybean, but showed no preference among snap bean or lima bean varieties. Although the physiological or morphological basis for this apparent host plant preference in $C$. trifurcata is not known, leaf pubescence could be an important factor. Trichomes are typically the first plant structures contacted by leaf-feeding insects when they encounter a plant (Smith 1989, Plant Resistance to Insects: A Fundamental Approach. Wiley, NY). High trichome densities in soybeans have been associated with decreased feeding injury by numerous insects (Chiang and Norris 1983, Environ. Entomol.12: 260 - 265; Elden and Lambert 1992, Crop Sci. 32:1187 1191; Lambert et al. 1992. Crop Sci. 32: 463 - 466; Cannon and Bach 1996, Environ. Entomol. 25: 1077 - 1082), including C. trifurcata (Lam and Pedigo, 2001, J. Econ. Entomol. 94: 1459 - 1463. Although this variable was not measured in our study, snap beans and lima beans typically have very low trichome densities, with an average of 0.03 trichomes per $\mathrm{cm}^{2}$ (Stenglein et al. 2004, Austr. J. Botany. 52, 73 - 80) relative to soybeans, which have from 20 to $>60$ trichomes per $\mathrm{cm}^{2}$ (Hongjun et al. 2010, Insect Sci. 17, 406 - 413).

Regardless of the mechanism, a preference for snap beans and lima beans over soybeans could have implications for beetle movement between crops, particularly when they are grown in close proximity to one another. Moreover, because snap beans are typically treated with systemic neonicotinoid seed treatments, which control beetles (Koch et al. 2005, Crop Prot. 24: 734 - 742), the snap beans could serve as a dead-end trap crop to reduce beetle numbers and potential BPMV spread in soybeans. However, additional field research on this topic is needed. 